\title{
Pengaruh Kadar Fly Ash terhadap Kuat Tekan pada High Volume Fly Ash Self Compacting Concrete (HVFA-SCC) pada Usia 90 Hari.
}

\author{
Hudha Pramudya Murti1), Agus Setiya Budi2), Sunarmasto3) \\ 1) Mahasiswa Program Studi Teknik Sipil Fakultas Teknik Universitas Sebelas Maret \\ 2),3) Pengajar Program Studi Teknik Sipil Fakultas Teknik Universitas Sebelas Maret \\ Jl. Ir. Sutami 36 A, Kentingan Surakarta 57126. Telp (0271) 647069, Fax 662118 \\ Email: hudapramudya@gmail.com
}

\begin{abstract}
Fly ash which incidentally is coal buming waste is often used as a cement substituent in large quantities because having chemical contains silica and alumina. These compounds form $\mathrm{C} 3 \mathrm{~S} 2 \mathrm{H} 3$ or tubermorite which is can increase concrete compressive strength because reacts with $\mathrm{Ca}(\mathrm{OH}) 2$, the result cement hydration process. These concepts when combined with SCC is called High Volume Fly Ash Self-Compacting Concrete (HVFAC-SCC). The purpose of this research is to know the effect of adding fly ash to the behaviour of concrete. The behaviour of concrete in this case is the ability to accept the load in terms of workability and compressive strength. This research used experimental method, which is HVFA-SCC used 3 variations of fly ash content of 50\%, 60\%, 70\% and tested of workability in the form of flow table test, L-box test and V-funnel test. While compressive strength of concrete will be tested at age 90 days. As a comparison of normal concrete used as $0 \%$ fly ash. The samples will be equated based on grade $50 \mathrm{Mpa}$. Each variation consists of 3 samples measuring $75 \mathrm{~mm} \times 150 \mathrm{~mm}$. The result of the research results obtained conclusion that is the compressive strength decrease with the increase percentage of fly ash
\end{abstract}

Keyword: fly ash, HVFA-SCC, workability, compressive strength

\begin{abstract}
Abstrak
Fly ash yang notabene adalah sisa pembakaran batu bara sering digunakan sebagai substituen semen dalam jumlah besar karena memiliki kandungan silica dan alumina. Senyawa tersebut membentuk $\mathrm{C}_{3} \mathrm{~S}_{2} \mathrm{H}_{3}$ atau tubermorite yang dapat menaikkan mutu beton akibat bereaksi dengan $\mathrm{Ca}(\mathrm{OH})_{2}$ hasil proses hidrasi semen. Konsep tersebut dipadukan dengan SCC sehingga membentuk High Volume Fly Ash Self-Compacting Concrete (HVFAC-SCC). Tujuan dari penelitian ini, untuk mengetahui pengaruh penambahan fly ash terhadap kinerja beton. Kinerja beton dalam hal ini adalah kemampuan dalam menerima beban ditinjau dari workability dan kuat desak. Penelitian ini menggunakan metode eksperimen, pada HVFA-SCC menggunakan 3 variasi kadar fly ash yaitu 50\%,60\%,70\% dan pengujian workability berupa flow table test, L-box test, dan $V$-funnel test. Sedangkan untuk kuat desak beton diuji pada umur 90 hari. Sebagai pembanding digunakan beton normal kadar fly ash $0 \%$. Sampel tersebut diseragamkan berdasarkan target mutu $40 \mathrm{MPa}$. Tiap variasi terdiri dari 3 sampel berukuran $75 \mathrm{~mm} \times 150 \mathrm{~mm}$. Hasil output penelitian diperoleh kesimpulan bahwa seiring bertambahnya persentase penambahan fly ash membuat kuat tekan beton semakin menurun.
\end{abstract}

Kata Kunci: fly ash, HVFA-SCC, workability, kuat tekan

\section{PENDAHULUAN}

Dunia konstruksi dewasa ini menunjukkan kinerja yang luar biasa dan akan terus meningkat tiap tahunnya. Kondisi ini dipengaruhi oleh beberapa faktor seperti pertumbuhan populasi, pesatnya urbanisasi serta peningkatan investasi di bidang properti. Salah satu dampak perkembangan dunia konstruksi adalah permintaan beton yang mengalami kenaikan secara signifikan, tercatat pada tahun 2016 permintaan beton mencapai angka 140 juta ton dan diprediksi akan terus meningkat tiap tahunnya mengingat gencarnya pembangunan yang dilakukan saat ini. Hal tersebut membuat dunia waswas, karena dengan meningkatnya permintaan beton maka produksi semen pun juga meningkat, padahal dalam produksi satu ton semen portland akan menghasilkan $\mathrm{CO}_{2}$ setara dengan 0,55 ton dan dalam produksinya memerlukan bahan bakar carbon yang juga menghasilkan emisi $\mathrm{CO}_{2}$ sebanyak 0,45 ton (Davidovits, 1994). Hal ini akan menimbulkan efek rumah kaca dan membuat kontribusi nyata terhadap global warming. Mengingat risiko yang ditimbulkan diperlukan langkah konkret untuk mencari alternatif lain yang dapat mengurangi atau menggantikan semen. Berbagai inovasi muncul ke permukaan satu persatu, salah satunya adalah penggunaan fly ash sebagai pengganti semen. Dalam beberapa penelitian, fly ash digunakan dalam jumlah kadar besar $(>50 \%)$ sebagai substituen semen. Konsep tersebut dikenal dengan High Volume Fly Ash Concrete (HVFAC). Penelitian kali ini adalah 
memadukan konsep tersebut dengan Self Compacting Concrete (SCC) atau sering disebut HVFA-SCC. Penelitian ini menggunakan 3 variasi persentase fly ash yaitu 50\%, 60\% dan 70\% pada benda uji silinder D 7,5cm x $15 \mathrm{~cm}$ dan diuji pada usia 90 hari untuk mengetahui kuat tekan pada High Volume Fly Ash Self Compacting Concrete (HVFA-SCC).

\section{TINJAUAN PUSTAKA}

Beton SCC merupakan beton yang mampu mengalir dengan beratnya sendiri yang dapat dicetak pada bekisting dengan tingkat penggunaan alat pemadat yang sangat sedikit atau tidak memerlukan pemadatan. Beton ini memanfaatkan pengaturan ukuran agregat, porsi agregat, dan zat admixture berupa superplaztizicer untuk mencapai kekentalan khusus yang memungkinkannya mengalir sendiri tanpa bantuan alat pemadat (Kukun Rusyandi, 2012).

Bahan tambah pozzolan seperti fly ash, silica fume, metakaolin, dan abu sekam telah digunakan sebagai bahan tambah atau pengganti semen karena dapat meningkatkan kekuatan dan ketahanan beton dibandingkan dengan semen portland biasa (Tjokrodimuljo, 2007).

\section{Pengujian}

\section{Tegangan Beton}

Tegangan pada beton dapat disebut kuat tekan beton, dimana besarnya beban maksimum yang dapat diterima persatuan luas. Pengujian dilakukan dengan memberikan beban/tekanan hingga benda uji runtuh. Untuk mengetahui tegangan hancur dari benda uji tersebut dapat dilakukan penghitungan melalui rumus berikut:

$\sigma=\frac{F}{A}$

dengan :

$\sigma \quad=$ tegangan beton benda uji silinder $(\mathrm{MPa})$

$\mathrm{F} \quad=$ gaya desak maksimum $(\mathrm{N})$

A $\quad=$ luas permukaan benda uji silinder $\left(\mathrm{mm}^{2}\right)$

\section{METODE PENELITIAN}

Metode yang digunakan dalam penelitian ini bersifat eksperimental dengan melakukan uji di Laboratorium Bahan, Laboratorium Struktur, dan Laboratorium Teknik Mesin Fakultas Teknik Universitas Sebelas Maret. Metode eksperimental ini digunakan untuk mengkaji beton segar berupa workability dan beton keras berupa kuat tekan. Benda uji yang digunakan dalam penelitian ini berbentuk silinder berukuran 7,5 cm x $15 \mathrm{~cm}$ dengan variasi jumlah kadar fly ash 50\%, 60\%, 70\%, dan $0 \%$ (beton normal). Benda uji yang digunakan tercantum pada Tabel 1.

Tabel 1. Hasil Pengujian Agregat Kasar

\begin{tabular}{cccc}
\hline No & Nama Benda Uji & Kadar Fly Ash & Jumlah ( buah ) \\
\hline 1 & HVFA-SCC. 90.50 & $50 \%$ & 3 \\
\hline 2 & HVFA-SCC. 90.60 & $60 \%$ & 3 \\
\hline 3 & HVFA-SCC. 90.70 & $70 \%$ & 3 \\
\hline 4 & Beton Normal & $0 \%$ & 3 \\
\hline
\end{tabular}

\section{HASIL DAN PEMBAHASAN}

\section{Hasil Pengujian Material}

Material yang digunakan pada penelitian ini sudah dilakukan uji lab untuk mengetahui sifat dan kandungan di dalamnya. Hasil pengujian material dapat dilihat pada tabel berikut:

Tabel 2. Hasil Pengujian Agregat Kasar

\begin{tabular}{clccc} 
No & Jenis Pengujian & Hasil Pengujian & Standar & Kesimpulan \\
\hline 1 & Absorbtion & $0,83 \%$ & - & - \\
\hline 2 & Apparent Specific Gravity & $2,6690 \mathrm{gr} / \mathrm{cm}^{3}$ & - & - \\
\hline 3 & Bulk Specific Gravity & $2,6109 \mathrm{gr} / \mathrm{cm}^{3}$ & - & - \\
\hline 4 & Bulk Specific SSD & $2,6327 \mathrm{gr} / \mathrm{cm}^{3}$ & $2,5-2,7 \mathrm{gr} / \mathrm{cm}^{3}$ & Memenuhi syarat \\
\hline 5 & Modulus Halus Butir & 8,3640 & $5-8$ & Memenuhi syarat \\
\hline \hline
\end{tabular}


Tabel 3. Hasil Pengujian Agregat Halus

\begin{tabular}{clccc}
\hline No & Jenis Pengujian & Hasil Pengujian & Standar & Kesimpulan \\
\hline 1 & Absorbtion & $0.83 \%$ & - & - \\
\hline 2 & Apparent Specific Gravity & $2,6690 \mathrm{gr} / \mathrm{cm}^{3}$ & - & - \\
\hline 3 & Bulk Specific Gravity & $2,6109 \mathrm{gr} / \mathrm{cm}^{3}$ & - & - \\
\hline 4 & Bulk Specific SSD & $2,6327 \mathrm{gr} / \mathrm{cm}^{3}$ & $2,5-2,7 \mathrm{gr} / \mathrm{cm}^{3}$ & Memenuhi syarat \\
\hline 5 & Modulus Halus Butir & 8,3640 & $5-8$ & Memenuhi syarat \\
\hline
\end{tabular}

Tabel 4. Komposisi Kimia Fly Ash

\begin{tabular}{lr}
\hline Formula & Concentration \\
\hline $\mathrm{SiO}_{2}$ & $39,69 \%$ \\
\hline $\mathrm{Al}_{2} \mathrm{O}_{3}$ & $13,23 \%$ \\
\hline $\mathrm{Fe}_{2} \mathrm{O}_{3}$ & $23,43 \%$ \\
\hline $\mathrm{TiO}_{2}$ & $1,60 \%$ \\
\hline $\mathrm{CaO}$ & $10,91 \%$ \\
\hline $\mathrm{MgO}$ & $3,93 \%$ \\
\hline $\mathrm{K}_{2} \mathrm{O}$ & $2,72 \%$ \\
\hline $\mathrm{P}_{2} \mathrm{O}_{5}$ & $1,13 \%$ \\
\hline $\mathrm{SO}_{3}$ & $1,81 \%$ \\
\hline $\mathrm{MnO}$ & $0,28 \%$ \\
\hline
\end{tabular}

\section{Mix Design}

Penelitian High Volume Fly Ash SelfCompacting Concrete (HVFA-SCC) menggunakan komposisi material penyusun beton yang sesuai dengan peraturan EFNARC 2005. Rekapitulasi mix design pada penelitian ini dapat dilihat pada Tabel 5

Tabel 5. Mix Design High Volume Fly Ash-Self Compacting Concrete dan Beton Normal

\begin{tabular}{lrrrr}
\hline \multirow{2}{*}{ Material } & \multicolumn{4}{c}{ Kode Benda Uji } \\
\cline { 2 - 5 } & HVFA90.50 & HVFA90.60 & HVFA90.70 & NC28 \\
\hline Persentase Fly Ash $(\%)$ & 50,00 & 60,00 & 70,00 & - \\
\hline Semen $\left(\mathrm{kg} / \mathrm{m}^{3}\right)$ & 250,00 & 200,00 & 150,00 & 400,00 \\
\hline Fly Ash $\left(\mathrm{kg} / \mathrm{m}^{3}\right)$ & 250,00 & 300,00 & 350,00 & 0,00 \\
\hline Kerikil $\left(\mathrm{kg} / \mathrm{m}^{3}\right)$ & 889,33 & 886,79 & 884,18 & 1156,70 \\
\hline Pasir $\left(\mathrm{kg} / \mathrm{m}^{3}\right)$ & 865,79 & 863,19 & 860,65 & 750,61 \\
\hline Air $\left(\mathrm{lt} / \mathrm{m}^{3}\right)$ & 135,00 & 135,00 & 135,00 & 120,00 \\
\hline Superplasticizer $\left(\mathrm{lt} / \mathrm{m}^{3}\right)$ & 10,00 & 10,00 & 10,00 & 4,00 \\
\hline
\end{tabular}

\section{Hasil Pengujian Beton Segar}

Tabel 6. Hasil Pengujian Beton Segar HVFA-SCC

\begin{tabular}{|c|c|c|c|c|c|}
\hline \multirow{2}{*}{$\begin{array}{c}\text { Jenis } \\
\text { Pengujian }\end{array}$} & \multirow{2}{*}{ Parameter } & \multicolumn{3}{|c|}{ Hasil Pengujian } & \multirow{2}{*}{$\begin{array}{c}\text { Persyaratan Beton SCC } \\
\text { (EFNARC 2002) }\end{array}$} \\
\hline & & $50 \%$ & $60 \%$ & $70 \%$ & \\
\hline \multirow{2}{*}{ Flow Table } & Diameter (mm) & 658,50 & 674,00 & 733,50 & $600-700 \mathrm{~mm}$ \\
\hline & $\mathrm{t}_{50}($ detik$)$ & 4,60 & 4,20 & 3,20 & $2-5$ detik \\
\hline$L-B o x$ & h2/h1 & 0,83 & 0,91 & 0,98 & $0,8-1,0$ \\
\hline \multirow{3}{*}{$V$-funnel } & $\mathrm{t}($ detik $)$ & 10,30 & 8,70 & 7,20 & $6-12$ detik \\
\hline & $\mathrm{T}_{5 \text { menit }}(\mathrm{detik})$ & 11,70 & 10,20 & 9,80 & \\
\hline & $\Delta \mathrm{t}(\mathrm{detik})$ & 1,40 & 1,50 & 2,60 & $0-3$ detik \\
\hline
\end{tabular}

Pada beton normal dilakukan pengujian slump dan didapat hasil adalah $11 \mathrm{~cm}$. 
Hasil Pengujian Berat Volume

Tabel 7. Hasil Pengujian Berat Volume

\begin{tabular}{|c|c|c|c|c|c|c|}
\hline No. & Benda Uji & $\begin{array}{l}\text { Diameter } \\
(\mathrm{mm})\end{array}$ & $\begin{array}{l}\text { Tinggi } \\
(\mathrm{mm})\end{array}$ & $\begin{array}{l}\text { Luas } \\
\left(\mathrm{mm}^{2}\right)\end{array}$ & Berat (gr) & $\begin{array}{l}\text { Berat volume } \\
\qquad\left(\mathrm{kg} / \mathrm{m}^{3}\right)\end{array}$ \\
\hline 1 & NC28.A & 75 & 150 & 4417,86 & 1603,00 & 2418,97 \\
\hline 2 & NC28.B & 75 & 150 & 4417,86 & 1608,00 & 2426,51 \\
\hline 3 & NC28.C & 75 & 150 & 4417,86 & 1627,00 & 2455,18 \\
\hline \multicolumn{6}{|c|}{ Rata-rata } & 2433,55 \\
\hline 4 & HVFA90.50.A & 75 & 150 & 4417,86 & 1615,00 & 2437,07 \\
\hline 5 & HVFA90.50.B & 75 & 150 & 4417,86 & 1610,00 & 2429,53 \\
\hline 6 & HVFA90.50.C & 75 & 150 & 4417,86 & 1624,00 & 2450,66 \\
\hline \multicolumn{6}{|c|}{ Rata-rata } & 2439,09 \\
\hline 7 & HVFA90.60.A & 75 & 150 & 4417,86 & 1450,50 & 2447,64 \\
\hline 8 & HVFA90.60.B & 75 & 150 & 4417,86 & 1431,10 & 2479,33 \\
\hline 9 & HVFA90.60.C & 75 & 150 & 4417,86 & 1451,30 & 2485,36 \\
\hline \multicolumn{6}{|c|}{ Rata-rata } & 2470,78 \\
\hline 10 & HVFA90.70.A & 75 & 150 & 4417,86 & 1454,80 & 2452,17 \\
\hline 11 & HVFA90.70.B & 75 & 150 & 4417,86 & 1419,60 & 2480,84 \\
\hline 12 & HVFA90.70.C & 75 & 150 & 4417,86 & 1418,20 & 2431,04 \\
\hline \multicolumn{6}{|c|}{ Rata-rata } & 2454,68 \\
\hline
\end{tabular}

\section{Kuat Tekan}

Tabel 8. Hasil Pengujian Kuat Tekan Benda Uji

\begin{tabular}{|c|c|c|c|c|c|c|}
\hline No. & Benda Uji & $\begin{array}{l}\text { Diameter } \\
(\mathrm{mm})\end{array}$ & $\begin{array}{l}\text { Tinggi } \\
\text { (mm) }\end{array}$ & $\begin{array}{l}\text { Luas } \\
\left(\mathrm{mm}^{2}\right)\end{array}$ & $\begin{array}{c}\text { Beban Maks } \\
(\mathrm{kN})\end{array}$ & $\begin{array}{c}\text { Kuat Desak } \\
(\mathrm{MPa})\end{array}$ \\
\hline 1 & NC28.A & 75 & 150 & 4417,86 & 222,46 & 50,35 \\
\hline 2 & NC28.B & 75 & 150 & 4417,86 & 230,91 & 52,26 \\
\hline 3 & NC28.C & 75 & 150 & 4417,86 & 266,30 & 60,32 \\
\hline \multicolumn{6}{|c|}{ Rata-rata } & 54,31 \\
\hline 4 & HVFA90.50.A & 75 & 150 & 4417,86 & 251,79 & 56,99 \\
\hline 5 & HVFA90.50.B & 75 & 150 & 4417,86 & 248,17 & 56,17 \\
\hline 6 & HVFA90.50.C & 75 & 150 & 4417,86 & 250,89 & 56,79 \\
\hline \multicolumn{6}{|c|}{ Rata-rata } & 56,65 \\
\hline 7 & HVFA90.60.A & 75 & 150 & 4417,86 & 198,83 & 45,01 \\
\hline 8 & HVFA90.60.B & 75 & 150 & 4417,86 & 182,81 & 41,38 \\
\hline 9 & HVFA90.60.C & 75 & 150 & 4417,86 & 193,07 & 43,71 \\
\hline \multicolumn{6}{|c|}{ Rata-rata } & 43,36 \\
\hline 10 & HVFA90.70.A & 75 & 150 & 4417,86 & 162,62 & 36,81 \\
\hline 11 & HVFA90.70.B & 75 & 150 & 4417,86 & 149,49 & 32,71 \\
\hline 12 & HVFA90.70.C & 75 & 150 & 4417,86 & 143,64 & 32,52 \\
\hline \multicolumn{6}{|c|}{ Rata-rata } & 34,01 \\
\hline
\end{tabular}




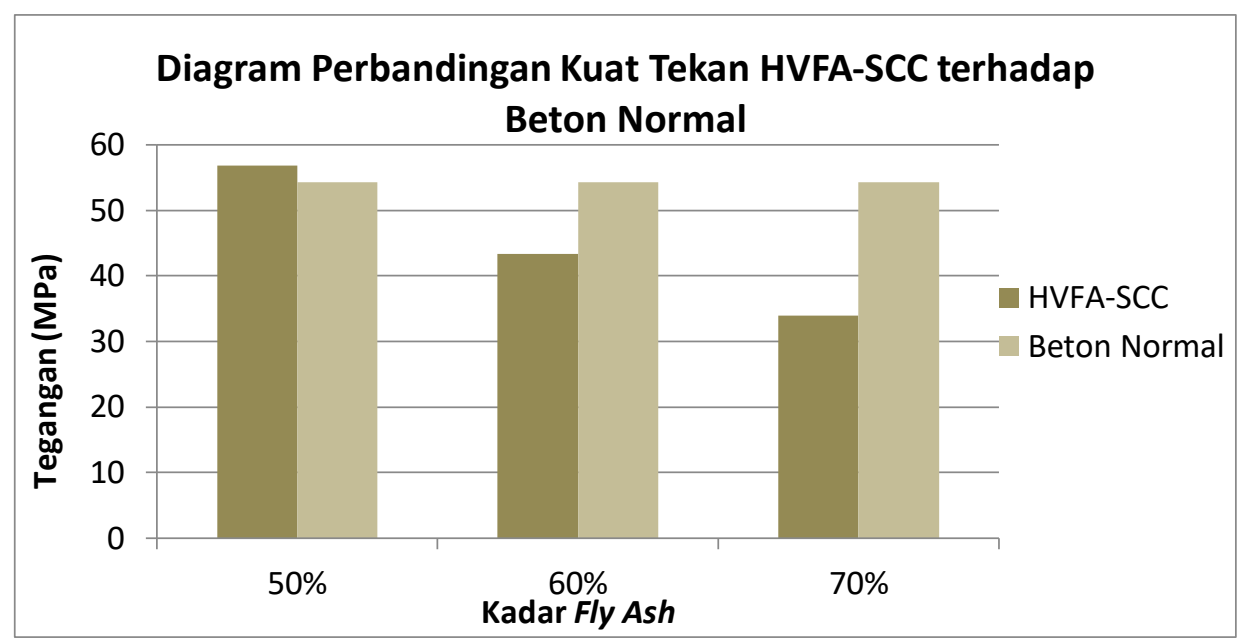

Gambar 1 Perbandingan Kuat Tekan HVFA-SCC terhadap Beton Normal

Adapun persentase kenaikan nilai kuat desak umur 90 hari dengan nilai kuat desak pada benda uji di usia 28 hari. Rekapitulasi kuat tekan beton dapat dilihat pada tabel berikut.

Tabel 9. Perbandingan Kuat Tekan Benda Uji Usia 28 dan 90 Hari

\begin{tabular}{ccccc}
\hline \multirow{2}{*}{ No. } & \multirow{2}{*}{ HVFA Kadar (Persen) } & \multicolumn{2}{c}{ Kuat Desak (MPa) } & \multirow{2}{*}{ Persentase kenaikan } \\
\cline { 3 - 4 } & & 28 hari & 90 hari & \\
\hline 1 & HVFA.50 & 49,86 & 56,65 & $13,62 \%$ \\
\hline 2 & HVFA.60 & 39,16 & 43,36 & $10,73 \%$ \\
\hline 3 & HVFA.70 & 23,17 & 34,01 & $46,78 \%$ \\
\hline
\end{tabular}

Hasil penelitian menunjukkan semakin tinggi persentase fly ash sebagai substituen membuat kuat tekan beton menurun. Hal tersebut terjadi akibat penurunan persentase semen sebagai bahan ikat utama dalam beton. Selain itu pada umur 90 hari, reaksi antara fly ash dengan hasil sekunder reaksi hidrasi semen yaitu $\mathrm{Ca}(\mathrm{OH})_{2}$ untuk membentuk C-S-H belum terjadi lebih optimal dibandingkan benda uji umur 28 hari sehingga membuat kuat tekan beton di 90 hari lebih tinggi.

\section{SIMPULAN}

Dari hasil pembahasan di atas dapat diambil beberapa kesimpulan sebagai berikut :

1. Flowability, Passing ability, dan segregation resistance akan meningkat seiring dengan bertambahnya penambahan fly ash.

2. Kuat tekan beton menurun seiring bertambahnya kadar fly ash.

3. Mutu beton di umur 90 hari lebih tinggi dibandingkan dengan umur 28 hari.

\section{UCAPAN TERIMA KASIH}

Ucapan terima kasih penulis sampaikan kepada Bapak Agus Setiya Budi, S.T., M.T. dan Bapak Ir Sunarmasto M.T., selaku dosen pembimbing dalam penelitian ini. yang mana telah memberikan arahan, masukan dan koreksi dengan penuh kesabaran. Rasa terima kasih penulis sampaikan khusus untuk tim Beton Sabar selaku tim kerja yang pantang menyerah.

\section{REFERENSI}

Andreas Nur Hadi. 2017."The Effect of Fly Ash Content for Stress-Strain Behavior of High Volume Fly ash - Self Compacting Concrete (HVFA-SCC)". Universitas Sebelas Maret.

Anonim. 2000. "SN1 03-2834-2000, "Tata Cara Pembuatan Rencana Campuran Beton Normal". Badan Standarisasi Nasional, Jakarta. 
Anonim. 2004. "SNI 15-2049-2004 Semen Portland”. Badan Standardisasi Nasional, Jakarta." Badan Standarisasi Nasional, Jakarta.

Anonim. "Standard Test Method for Passing Ability of Self-Consolidating Concrete by J-Ring”, American Society for Testing of Concrete's.". ASTM C 1621M. 1991.

Anonim. "Standard Standard Specification for Concrete Aggregates". ASTM C33. 1991.

Anonim. "Standard Test Method for Compressive Strength of Concrete", American Society for Testing of Concrete's. ASTM C39/C39M. 1991.

Anonim. "Standard Test Method for Fly Ash and Row or calcined Natural Pozzolan for Use as a mineral Admixture in Portland Cement Concrete", American Society for Testing of Concrete's". ASTM C 618-93. 1991.

Anonim. "Specification and Guidelines for Self - Compacting Concrete". EFNARC. 2002.

Avri Priatma. 2012.”Pengaruh Kadar Fly Ash sebagai Pengganti Sebagian Semen terhadap Kuat Tarik Belah dan Modulus of Rupture pada High Volume Fly Ash-Self Compacting Concrete". Universitas Sebelas Maret.

Davidovits k. 1994b. "Properties of Geopolymer Cements", Proceeding First International Conference on Alkaline Cements and Concrete, Scientific Research Institute on Binders And Materials". Kiev state technical university, kiev, ukraina, hal 131-149.

Dedi Septian. 2011."Effect of Fly Ash Content as Cement Subtitution On Elastic Modulus of High Volume Fly Ash-Self Compacting Concrete". Universitas Sebelas Maret.

Gere and Timoshenko. "Mekanika Bahan". Erlangga : Jilid II Edisi 4. Jakarta.

Kardiyono Tjokrodimuljo. 1996.”Teknologi Beton”.Fakultas Teknik Universitas Gadjah Mada. 